\title{
Cutaneous anthrax associated with handling carcasses of animals that died suddenly of unknown cause: Arua District, Uganda, January 2015-August 2017
}

\section{Freda Loy Aceng ( $\square$ faceng@musph.ac.ug )}

Republic of Uganda Ministry of Health https://orcid.org/0000-0003-3029-8947

\section{Alex Riolexus Ario}

Uganda Public Health Fellowship Program

Phoebe Hilda Alitubeera

Uganda Public Health Fellowship Program

\section{Daniel Kadobera}

Uganda Public Health Fellowship Program

\section{Musa Sekamatte}

Zoonotic Disease Coordination Office

\section{Denis Okethwangu}

Uganda Public Health Fellowship Program

Lilian Bulage

Uganda Public Health Fellowship Program

Julie R. Harris

Workforce and Institute Development Branch, Division of Global Health Protection, Center for Global Health, US Centers for Disease

Control and Prevention

\section{Willy Nguma}

Arua District Local Government

\section{Deo Birungi Ndumu}

Ministry of Agriculture, Animal Industry and Fisheries

\section{Joshua Buule}

Uganda Virus Research Institute

\section{Luke Nyakarahuka}

Uganda Virus Research Institute

Bao-Ping Zhu

Workforce and Institute Development Branch, Division of Global Health Protection, Center for Global Health, US Centers for Disease Control and Prevention; US Center for Disease Control and Prevention, Kampala

\section{Research}

Keywords: Cutaneous anthrax, Arua, Uganda

Posted Date: June 23rd, 2020

DOI: https://doi.org/10.21203/rs.2.22358/v2

License: @ (1) This work is licensed under a Creative Commons Attribution 4.0 International License. Read Full License

Version of Record: A version of this preprint was published at PLOS Neglected Tropical Diseases on August 23rd, 2021. See the published version at https://doi.org/10.1371/journal.pntd.0009645. 


\section{Abstract}

Background : Anthrax is a zoonotic vaccine-preventable disease that can be transmitted to humans from infected animals. During May-June 2017, three persons with probable cutaneous anthrax were reported in Arua District, Uganda; one died. All had recently handled carcasses of livestock that died suddenly. During July, a bull in the same community died suddenly. A skin lesion from the deceased person and a blood sample from the bull tested positive by PCR for Bacillus anthracis. The aim of this investigation was to establish the scope of the problem, identify exposures associated with illness, and recommend evidence-based control measures.

Methods: We defined a probable case as acute onset of a papulo-vesicular skin lesion subsequently forming an eschar in a resident of Arua District during January 2015-August 2017. A confirmed case was a probable case with a skin sample testing positive by polymerase chain reaction (PCR) for B. anthracis. We identified cases by medical record review and active community search. In a casecontrol study, we compared exposures between case-patients and frequency- and village-matched asymptomatic controls. We interviewed key animal health staff to learn about livestock deaths.

Results: We identified 68 case-patients (67 probable, 1 confirmed), and 2 deaths. Cases occurred throughout the three-year period, peaking during dry seasons. All cases occurred following sudden livestock deaths in the villages. Case-patients came from two neighboring sub-counties: Rigbo (attack rate $(A R)=20.1 / 10,000$ population) and Rhino Camp $(A R=2.1 / 10,000)$. Males $(A R=17 / 100,000)$ were more affected than females ( $A R=0.52 / 100,000)$. Persons aged 30-39 years ( $A R=26 / 100,000$ population) were most affected. Among all cases and 136 controls, skinning (OR M-H =5.0,95\% Cl: $2.3-11)$, butchering (OR $\mathrm{M}-\mathrm{H}=22,95 \% \mathrm{Cl}$ : 5.5-89), and carrying the carcass of livestock that died suddenly $(\mathrm{OR} \mathrm{M}-\mathrm{H}=6.9,95 \% \mathrm{Cl}$ : $3.0-16)$ were associated with illness.

Conclusions: Exposure to carcasses of animals that died suddenly was a likely risk factor for cutaneous anthrax in Arua District during 2015-2017. We recommend public education about signs and symptoms of anthrax, prompt treatment of illness following exposure to animals that died suddenly, and safe disposal of the carcasses. In addition, the anthrax burden in livestock should be investigated to inform the cost-effectiveness of livestock vaccination.

\section{Background}

Anthrax is an acute zoonotic disease caused by the Gram-positive spore-forming bacteria Bacillus anthracis [1]. Most anthrax infections occur among animals, with occasional spread to humans [2]. Human infections often result from handling and / or consuming meat of infected livestock [1]. Humans may develop cutaneous, inhalational, gastrointestinal, and injection-associated infection [1] [3]. Cutaneous anthrax accounts for $95 \%$ of human cases and is characterized by itching and skin lesions starting 1-7 days after infection; the lesions eventually form depressed eschars [1]

Although infrequently documented, anthrax is likely common among animals in Uganda; the frequency of human infections is unclear. In 2004, an anthrax outbreak killed hundreds of animals, including hippo, zebras, elephants, and other wildlife in Queen Elizabeth National Park, in southwestern Uganda [4]. Reports of humans dying after eating meat from dead hippos were unconfirmed [4] [5] [6]. A 2010 report documented nearly 100 deaths from anthrax among hippos and buffalo in the same park [4], and in 2011, an anthrax outbreak was reported in the nearby Sheema District, affecting both humans and cattle [7].

On 7 May 2017, the Arua District Surveillance Officer was informed about two probable cutaneous anthrax human cases from Rigbo sub-county. The patients, siblings aged 6 and 12 years, presented to a health center with acute onset of skin lesions with depressed blackened centers and edema. Both children reported recently handling and consuming meat from a cow that died suddenly. Although the district health officers investigated, no samples were taken and the cases were unconfirmed. Both children recovered after antibiotic treatment, and no further cases occurred in the family.

On 5 June 2017, the Uganda Ministry of Health $(\mathrm{MoH})$ was notified about the death of a 35-year-old resident of Rhino Camp sub-county (Mr. A, unconnected to the two children described above) who presented to a health facility on 4 June with restlessness, sweating, confusion, difficulty breathing, and an eschar on his back. He deteriorated quickly, and died on 5 June. According to his neighbor, he had carried and butchered meat from a cow that died suddenly on 11 May, and developed itching on the affected site on 14 May. No other animals fell ill on the farm; a neighbor also handled the meat, but did not fall ill. The affected site on Mr. A's back turned into a papulovesicular lesion, which progressed into a black eschar. After initially trying herbal remedies to address the problem, the patient had sought medical care at a local clinic on 21 May. At the clinic, he was diagnosed with suspected Herpes Zoster infection and given intravenous ceftriaxone; the rationale for this treatment is not clear. A skin lesion sample from Mr. A on 5 June tested positive for

Page 2/11 
anthrax by PCR at the Uganda Virus Research Institute. On 24 July, a bull cow residing in the same community as Mr. A died suddenly. Microscopic examination of a tissue sample from the bull showed Gram-positive rods, consistent with $B$. anthracis, and PCR of the tissue sample confirmed $B$. anthracis. During August 2017, a team from the Ministry of Health traveled to the area to establish the scope of the problem, identify exposures associated with transmission, and recommend evidence-based control measures.

\section{Methods}

\section{Study setting}

Arua District is located in northwestern Uganda and is bordered by the Democratic Republic of the Congo (DRC) on its western border, and is $80 \mathrm{~km}$ from the South Sudan Border to the north. Arua District has a total population of approximately 820,500, nearly one in five of whom are refugees (most from South Sudan) [8]. More than $80 \%$ of the households are engaged in agriculture, and the district has multiple rich wildlife reserves [8] [9].

\section{Case definition and case finding}

Early interviews with district authorities and local council chairpersons indicated that probable cutaneous anthrax cases had been occurring in the area since at least 2015. Therefore, we defined a probable case as acute onset of painless skin lesions with progression from papular to vesicular before forming an eschar (with a depressed blackened center) in a resident of Arua District from January 2015-August 2017. A confirmed case was a probable case with laboratory-confirmed B. anthracis by PCR of a skin lesion sample.

\section{Analyses}

The eschar was sampled by carefully lifting the eschar's outer edge; a sterile swab was inserted, then slowly rotated for 2-3 seconds beneath the edge of the eschar..

The fresh swab sample was used for genomic and plasmid DNA extraction using commercially-available DNA Promega DNA IQ ${ }^{\mathrm{TM}}$ system (Promega corporation, USA) following manufacturer's instructions.

Protective antigen (PA) primers and probe targeting pX01 plasmid, capsule (Cap) primers and probe targeting pXO2 plasmid and RNase $P$ primers [10] targeting the human ribonuclease $P$ gene were used in three separate reactions tubes per sample. We used CDCsupplied primers PA-Forward: CGG ATC AAG TAT ATG GGA ATA TAG CAA, PA-Reverse: CCG GTT TAG TCG TTT CTA ATG GAT, PA-Probe: FAM-CTC GAA CTG GAG TGA AGT GTT ACC GCA AAT-BHQ1 and for Capsule; Cap-Forward: ACG TAT GGT GTT TCA AGA TTC ATG, CapReverse: ATT TTC GTC TCA TTC TAC CTC ACC and Cap-Probe: FAM-CCA CGG AAT TCA AAA ATC TCA AAT GGC AT-BHQ1. For RNaseP: RP-Forward: AGA TTT GGA CCT GCG AGC G, RP-Reverse: GAG CGG CTG TCT CCA CAA GT and RP-Probe: FAM-TTC TGA CCT GAA GGC TCT GCG CG-BHQ1.

The PCR mixture ( $25 \mathrm{~mL}$ total reaction volume) contained $12.5 \mathrm{ml}$ of Promega mastermix 2x M7505 (Promega corporation, WI USA) $0.1 \mathrm{mM}$ of each probe and $0.3 \mathrm{mM}$ of each primer and $5 \mathrm{ml}$ of DNA template. The RNaseP primers were used to confirm the presence of human DNA in the sample extracts. We used DNA from the pLepBaBp+, provided by CDC, as a positive control, and a non-template negative control (nuclease-free water). Each primer set was run in a separate PCR tube. Template DNA was initially denatured by heating at $95^{\circ} \mathrm{C}$ for $10 \mathrm{~min}$, followed by 40 cycles of denaturation at $95^{\circ} \mathrm{C}$ for $15 \mathrm{sec}$, annealing and primer extension at $60^{\circ} \mathrm{C}$ for $1 \mathrm{~min}$ using the Stratagene MX3000P Real-time PCR system (Agilent Technologies USA, Santa Clara, California) [10]. Confirmed positive samples were those that amplified with both the pXO1 and pXO2 primers as well as the RNase $\mathrm{P}$ targets.

\section{Descriptive epidemiology}

Interviews with the Arua District Health Officer (DHO) and District Veterinary Officer (DVO) suggested that Rhino Camp and Rigbo subcounties were the source of most probable cases reported. As a result, we limited our study to these two sub-counties. We conducted medical record reviews at the health centers in Rhino Camp and Rigbo to identify both previous and current probable anthrax cases. In 
addition, with the help of community health workers (CHW), the Assistant Animal Husbandry Officer, and health facility staff, we actively searched for case-patients. We interviewed the District Veterinary Officer (DVO), the Animal Husbandry Officer, and local council leaders about sudden livestock deaths to identify suspect animal anthrax cases. A suspected animal anthrax case was defined as an animal that died suddenly and had an epidemiologic link to a human case. This was mostly based on the comparison with the probable human anthrax cases and their exposure to those animals prior to symptom onset.

We interviewed probable anthrax cases or their caregivers with a standardized case investigation form to collect data on demographic characteristics, date of symptom onset, clinical characteristics, livestock ownership, recent livestock deaths, and cause of livestock deaths. In addition, we asked about contact with livestock carcasses before their illness onset, including case-patient involvement in skinning/butchering a dead animal carcass, preparing and eating meat from a dead animal, carrying a dead animal and contact with live animals (milking). We described the probable anthrax case-patients on the basis of age, sex, place, time, and clinical characteristics. Using population data obtained from the district, we calculated attack rates (AR) by person (sex and age) and place (sub-county and parish). For livestock, we collected data on date and location of livestock deaths. We used Quantum Geographic Information System (QGIS version 2.8.1) [11]to construct maps to show the locations of case-patients and livestock deaths in Arua District. We obtained latitude and longitude of individual case-patient residences.

\section{Analytical study}

We conducted a frequency-matched case-control study using two randomly-selected neighborhood controls (independent of sex or age, but living in the same village as the case-patient at the time of diagnosis) for each case. A control was an individual with no history of probable anthrax during January 2015-August 2017. We interviewed case-patients and controls about activities during the 14 days before the case-patient's illness.

\section{Data analysis}

Data were entered and analyzed using Epi-Info version 7.2.1.0 [12]. To account for the matched study design, we used the MantelHaenszel method [13] to estimate odds ratios (OR) and their $95 \%$ confidence intervals.

\section{Results}

\section{Descriptive epidemiology}

Overall, we identified 67 probable and one confirmed case-patient; two died [case-fatality rate (CFR) $=2.9 \%$ ]. Of the 68 case-patients, 67 $(99 \%)$ presented with edema, and 62 (91\%) with swollen lymph nodes (Figure 1). The most common lesion sites were on the hand (83\%) or back $(4.4 \%)$. Among the cases, $63(93 \%)$ reported that they had sought treatment for their illness; data on the specific treatments were not obtained. The epidemic curve showed noticeable peaks during March and April of 2016 and May 2017 (Figure 2). Exposure to the meat or carcass of livestock that had died suddenly was reported before illness onset for all case-patients; 5 were exposed to goats and 63 to cows.

The median age of the case-patients was 34 years (IQR: 26-42). Persons aged 30-39 years were most affected (AR: 26/100,000 population), and males (AR: 25.7/100,000 population) were more affected than females (AR: $0.75 / 100,000$ population) p $<0.0001$ (Table 1). The overall attack rate was $13 / 10,000$ population across the two sub-counties. Rigbo sub-county was more affected $(A R=23.1 / 10,000)$ than Rhino Camp sub-county $(A R=2 / 10,000) p<0.0001$ (Figure 3). In general, the human case-patient residences appeared to be in close proximity (within a few meters) to the locations of the reported livestock deaths (Figure 4).

\section{Hypothesis generation findings}

Of the 39 case-patients interviewed during hypothesis generation, 37 (95\%) reported having butchered livestock that died suddenly (within hours of the animal's apparent illness onset), 35 (90\%) carried carcasses of livestock that died suddenly, 32 (82\%) skinned dead livestock that died suddenly, and one (2.6\%) slept on hides. Further investigation revealed that the six and 12-year old children whose illnesses were part of the initial reported cluster had also participated in handling and eating meat from the carcass of a cow that died suddenly. Their father, who had butchered the cow, was also a case-patient. We therefore hypothesized that butchering/carrying and 
skinning carcasses of livestock that died suddenly were likely risk factors for infection in this area. Although some case-patients reported that they had gastrointestinal illnesses as well, none were specific enough to classify as possible gastrointestinal anthrax.

\section{Case-control study findings}

We enrolled 68 case-patients and 136 controls in the case-control study. Median age of case-patients was 34 years (IQR: 26-42) and for control-persons was 30 years (IQR: $24.5-41)$; $97 \%$ of case-patients, and $93 \%$ of control-persons were male $(p=0.25)$. All case-patients (100\%) and most control-persons (99\%) worked in contact with soil; $99 \%$ of case-patients and $96 \%$ of controls lived in homes with dirt floors (that is unfinished floors).

In the case-control study, 57 (84\%) case-patients and $72(53 \%)$ control-persons skinned animals that died suddenly $\left(\mathrm{OR}_{\mathrm{M}-\mathrm{H}}=5.0,95 \% \mathrm{Cl}\right.$ : $2.3-11)$. Sixty-five (96\%) case-patients and $76(56 \%)$ control-persons butchered carcasses of animals that died suddenly $\left(\mathrm{OR}_{\mathrm{M}-\mathrm{H}}=22\right.$, 95\%Cl: 5.5-89); 61 (90\%) case-patients and 74 (54\%) control-persons carried the carcass of an animal that died suddenly $\left(\mathrm{OR}_{\mathrm{M}-\mathrm{H}}=6.9\right.$, 95\%Cl: 3.0-16) (Table 2). Sixty-six (97\%) case-patients and 82 (60\%) control-persons reported that they had at least one of these exposures $\left(\mathrm{OR}_{\mathrm{M}-\mathrm{H}}=22,95 \% \mathrm{Cl}=5-104\right)$. Among the 2 case-patients who did not have any of these exposures (children ages 1 and 3 years), both had reportedly eaten meat from a cow that had died suddenly.

\section{Key informant interviews}

Arua District Veterinary Office recommends that when an animal dies outside the context of slaughter of a healthy animal, the community should notify the sub-county or district authorities, who decide whether or not to take a sample before safe burial of the carcass. However, interviews with key informants, including the District Veterinary Officer (DVO), the Animal Husbandry Officer, and local council leaders revealed that such livestock deaths are rarely notified to the authorities. Rather, residents frequently skinned and butchered the animals, so as not to waste the meat. The informants also indicated that thorough smoking of the meat before consumption is a typical practice.

\section{Discussion}

Cutaneous anthrax cases in this region of Uganda during 2015-2017 appear to have been caused by skinning, butchering and carrying carcasses of infected animals that died suddenly. The 68 patients represent the largest collection of cutaneous anthrax cases ever reported in Uganda. Although a large number of probable cases were unconfirmed, the laboratory confirmation of anthrax from a dead bull and a human in the same community strongly suggests that probable cases were likely to be anthrax. Clinical signs of casepatients were also characteristic of cutaneous anthrax.

Handling carcasses of animals with suspected and confirmed anthrax has previously been established as a risk factor for cutaneous anthrax [14][15][16] [17][18][19]. The location of the black eschars for most case-patients - on the hands and back - has also been observed in other studies demonstrating livestock-human transmission of anthrax [14], and is likely related to animal carcasses being carried over the shoulder. The community practice of smoking meat before consumption may have prevented cases of gastrointestinal anthrax. Whether or not this was protective is difficult to confirm; vegetative forms of $B$. anthracis are easily killed during normal cooking, but spores are much more resistant to adverse conditions and require heating to at least $100^{\circ} \mathrm{C}$ for 15 minutes for inactivation [20]. Although we were unable to identify any gastrointestinal anthrax cases, illnesses might have been missed at health facilities or otherwise unreported.

Adult males were most affected in this cluster of infections. This is unsurprising, as this group is most likely to be engaged in exposures to animal carcasses. However, two case-patients were under five years of age. For these case-patients, the only two not involved in direct contact with livestock carcasses, infection may have occurred when spores were brought into the house by a parent or other contact involved in skinning, carrying, butchering, or preparing the meat. This type of exposure has been described previously with pediatric anthrax cases [21] and may explain the illnesses among the youngest case-patients.

Although probable cases had been occurring throughout the study period, the Ministry of Health was only alerted to these cases in mid2017. Anthrax testing is possible in Uganda, but it is infrequent because of incomplete reporting in veterinary surveillance systems, knowledge gaps among healthcare workers about anthrax and limited access to laboratory services. Because of the infrequent testing, both human and veterinary anthrax are almost certainly underreported in Uganda. Investigation of probable cases over a longer period (i.e., before 2015) or a prospective study could shed some light on the degree of underreporting. 
The epidemic curve showed noticeable peaks in human cases for two years during March-May, which corresponds with the dry season in Uganda. During the dry season, livestock may be at increased risk of contracting anthrax from soil due to increased exposure to spores in soil/dust through close grazing and looser soil [22]. In addition, stressors, such as poor nutrition or overheating and reduced resource availability, may lead to increased animal density in localized areas, such as along river banks, and increase the possibility of getting infected (15). For humans, food scarcity during the dry season may also force them to seek alternate sources of food, which could lead to their eating meat that they might otherwise avoid.

Cutaneous anthrax cases have been reported at the animal-human interface in several other regions globally including Bhutan, the Republic of Georgia, Kenya, and Tanzania [14] [17] [19] [24][25]. In a household survey in Zambia conducted after an anthrax outbreak linked to eating infected hippo meat, $23 \%$ of respondents mentioned that they would eat meat from dead animals again, despite the risk, due to food shortages [25]. Although we did not systematically collect data on this, several respondents reported to us anecdotally that they could not afford butchery-sourced meat.

Cutaneous anthrax is usually curable with prompt antibiotic therapy; approximately $10-20 \%$ of untreated patients die [26]. Although this therapy is readily available in Uganda, anecdotal evidence suggests that not all physicians are familiar with the presentation, and misdiagnosis can lead to delays in appropriate treatment. The late care-seeking behavior and subsequent difficulty with diagnosis of Mr. A likely contributed to his eventual death. Although most patients in this outbreak reported that they sought and received treatment, apart from Mr. A, we were unable to assess whether or not they were diagnosed and treated correctly.

The number of human cases and the time period over which they occurred also suggest more widespread livestock anthrax in this region, something that could potentially be prevented by animal vaccination. Effective herd immunity against anthrax in cattle requires at least $80 \%$ of the animals in an area to be vaccinated [27]. During an outbreak, all livestock in areas around the affected area should be vaccinated [27]. Despite anthrax being considered a priority zoonotic disease in Uganda, mass animal vaccinations are not currently done, primarily due to the low number of reported cases, nor are reactive vaccinations done during an outbreak. While farmers can choose to vaccinate their animals privately, many do not. No national guidelines are currently in place requiring livestock vaccination. The development of such guidelines would be dependent upon knowledge about its cost-effectiveness, which would depend on the true incidence of the disease. In Zimbabwe, the government previously conducted national annual anthrax vaccination campaigns for livestock, but currently vaccinations are restricted to high-risk areas only. In spite of this, livestock producers in Zimbabwe are advised to ensure that farm animals are vaccinated against anthrax annually [27].

\section{Limitations}

Because we conducted the investigation retrospectively, there is a possibility of recall bias including symptoms and date of onset, hence masking the actual anthrax prevalence in the district. In addition, it is likely that some cases were missed, which would have led to an underestimation of the magnitude of the outbreak. It is also possible that some were not true anthrax, leading to an overestimation. We had sparse data about the livestock deaths, preventing certainty that they were due to anthrax. In addition, we could not confirm the vast majority of cases, nor did we identify any cases of gastrointestinal anthrax. Although some patients had nonspecific gastrointestinal illnesses at the time of investigation, many were already taking antibiotic therapy, rendering sample testing ineffective. It is possible that gastrointestinal anthrax occurred and was missed.

\section{Conclusion And Recommendations}

The cutaneous anthrax cases occurring over a 3-year period in Uganda were associated with handling carcasses of animals that died suddenly. The district set up a One Health structure (a collaboration between human and veterinary health departments, including a single laboratory that processes both human and veterinary samples) to facilitate epidemic preparedness and response as a result of this outbreak. We recommended education of the public and of healthcare workers about signs and symptoms of anthrax, prompt treatment of illness following exposure to animals that died suddenly, safe disposal of animals that died suddenly, consumption of meat only from slaughtered healthy animals inspected by a trained veterinarian, and investigations to establish the risk factors for anthrax transmission in animals. Vaccination of livestock in the district may be warranted; however, a burden study would inform costeffectiveness.

\section{Abbreviations}

CDC: Centers for Disease Control and Prevention. DVO: District Veterinary Officer. HC: Health Center. PCR: Polymerase Chain Reaction. 


\section{Declarations}

\section{Ethics approval and consent to participate}

This investigation was in response to a public health emergency and was therefore determined to be non-research. The MoH through the office of the Director General of Health Services gave the directive and approval to investigate this outbreak. Additionally, the Centers for Disease Control and Prevention also determined that this activity was not human subjects' research, and its primary intent was public health practice or a disease control activity (specifically, epidemic or endemic disease control activity). We obtained verbal informed consent and assent from case-patients and/or their close relatives in case of death. We obtained verbal informed consent from case-patients $\geq 18$ years. For case-patients $<18$ years, we obtained verbal informed assent and verbal informed consent from their care takers. We obtained verbal informed consent and assent in the local languages. We informed participants that their participation was voluntary and their refusal would not result in any negative consequences. We used unique identifiers to ensure confidentiality. We did the same for the controls.

\section{Consent for publication}

Not applicable.

\section{Availability of data and material}

The datasets used and analyzed during this study belong to the Uganda Public Health Fellowship Program and are available from the corresponding author on reasonable request and upon permission from the Uganda Public Health Fellowship Program.

\section{Competing interests}

The authors declare that they have no competing interests.

\section{Funding}

This project was supported by the United States President's Emergency Plan for AIDS Relief (PEPFAR) through the US Centers for Disease Control and Prevention, Cooperative Agreement number GH001353-01 through Makerere University School of Public Health to the Uganda Public Health Fellowship Program, Ministry of Health. Its contents are solely the responsibility of the authors and do not necessarily represent the official views of the US Centers for Disease Control and Prevention/the Agency for Toxic Substances and Disease Registry, the Department of Health and Human Services, Makerere University School of Public Health, or the Uganda Ministry of Health.

\section{Authors' contributions}

FLA, ARA, PHA, DK, WN and DO carried out the outbreak investigation. JB and LK confirmed the specimens. ARA, DK, DBN and BPZ provided technical support during the outbreak investigation. FLA conceptualized the manuscript idea and took lead in writing the manuscript. ARA, LB, JRH, PHA, DK, BPZ, DO, WN, DBN and MS participated in manuscript writing and reviewed the manuscript for intellectual content and scientific integrity. All authors read and approved the final manuscript.

\section{Acknowledgements}

We would like to thank the Arua District Health Office, District Veterinary Office, Ministry of Health, National Animal Disease Diagnostics and Epidemiology Center (NADDEC) and US Centers for Disease Control and Prevention (US CDC) for the technical support during the investigation and response to this outbreak.

\section{References}

1. Heymann DL. Control of Communicable Diseases Manual. 20th edition. 2015.

2. WHO | Anthrax. WHO. http://www.who.int/ith/diseases/anthrax/en/. Accessed 15 Aug 2018.

3. Beatty ME, Ashford DA, Griffin PM, Tauxe RV, Sobel J. Gastrointestinal anthrax: review of the literature. Arch Intern Med. 2003;163:2527-31. 
4. Wafula MM, Patrick A, Charles T. Managing the 2004/05 anthrax outbreak in Queen Elizabeth and Lake Mburo National Parks, Uganda. African Journal of Ecology. 2008;46:24-31.

5. SciDev.Net. Uganda battles deadly anthrax outbreak. SciDev.Net. http://www.scidev.net/index.cfm? originalUrl=/global/health/news/uganda-battles-deadly-anthrax-outbreak.html\&. Accessed 26 Jul 2018.

6. Driciru M, Rwego IB, Asiimwe B, Travis DA, Alvarez J, VanderWaal K, et al. Spatio-temporal epidemiology of anthrax in Hippopotamus amphibious in Queen Elizabeth Protected Area, Uganda. PLOS ONE. 2018;13:e0206922.

7. Coffin JL, Monje F, Asiimwe-Karimu G, Amuguni HJ, Odoch T. A One Health, participatory epidemiology assessment of anthrax (Bacillus anthracis) management in Western Uganda. Soc Sci Med. 2015;129:44-50.

8. Uganda Investment Authority. Arua District Investment profile. 2017. http://www.ugandainvest.go.ug/wpcontent/uploads/2017/07/Arua-for-web.pdf. Accessed 27 Aug 2018.

9. Arua Town. Fortune Of Africa - Uganda. http://fortuneofafrica.com/ug/arua-town/. Accessed 25 Oct 2018.

10. Ellerbrok H, Nattermann H, Ozel M, Beutin L, Appel B, Pauli G. Rapid and sensitive identification of pathogenic and apathogenic Bacillus anthracis by real-time PCR. FEMS Microbiol Lett. 2002;214:51-9.

11. QGIS. https://www.qgis.org/en/site/.

12. Center for Disease Control and Prevention. Epi Info. https://www.cdc.gov/epiinfo/index.html.

13. McDonald J. Handbook of Biological Statistics. http://www.biostathandbook.com/cmh.html.

14. Al NKT et. Investigation and Control of Anthrax Outbreak at the Human-Animal Interface, Bhutan, 2010 - Volume 20, Number $9-$ September 2014 - Emerging Infectious Diseases journal - CDC. doi:10.3201/eid2009.140181.

15. Hossain MM, Rahman M, Shamim RK. Human cutaneous anthrax in Bangladesh: a case-control study. 2013. http://www.onehealthnetwork.asia/sites/onehealthnetwork.asia/files/upload/Bangladesh\%20CIP_Human\%20Anthrax_131202.pdf.

16. Bazeyo W, Lukwago L, Wamala J, Obayo S, Bua J, Ecumu J, et al. Suspected outbreak of cutaneous anthrax in Kasese district, the investigation and response, April to May 2007. East Afr J Public Health. 2009;6:235-9.

17. Kasradze A, Echeverria D, Zakhashvili K, Bautista C, Heyer N, Imnadze P, et al. Rates and risk factors for human cutaneous anthrax in the country of Georgia: National surveillance data, 2008-2015. PLoS One. 2018;13. doi:10.1371/journal.pone.0192031.

18. Siddiqui MA, Khan MAH, Ahmed SS, Anwar KS, Akhtaruzzaman SM, Salam MA. Recent outbreak of cutaneous anthrax in Bangladesh: clinico-demographic profile and treatment outcome of cases attended at Rajshahi Medical College Hospital. BMC Res Notes. 2012;5:464.

19. Muturi M, Gachohi J, Mwatondo A, Lekolool I, Gakuya F, Bett A, et al. Recurrent Anthrax Outbreaks in Humans, Livestock, and Wildlife in the Same Locality, Kenya, 2014-2017. Am J Trop Med Hyg. 2018;99:833-9.

20. FAQs on anthrax and possible contamination of foods with Bacillus anthracis - BfR FAQ, 22 October 2014. :3.

21. Cutaneous Anthrax Associated with Drum Making Using Goat Hides from West Africa - Connecticut, 2007. https://www.cdc.gov/mmwr/preview/mmwrhtml/mm5723a3.htm. Accessed 22 Feb 2019.

22. World Health Organization, International Office of Epizootics, Food and Agriculture Organization of the United Nations, editors. Anthrax in humans and animals. 4th ed. Geneva, Switzerland: World Health Organization; 2008. https://www.who.int/csr/resources/publications/anthrax_web.pdf. Accessed 15 Feb 2019.

23. Turner WC, Imologhome P, Havarua Z, Kaaya GP, Mfune JKE, Mpofu IDT, et al. Soil ingestion, nutrition and the seasonality of anthrax in herbivores of Etosha National Park. Ecosphere. 2013;4:art13.

24. Mwakapeje ER, Høgset S, Fyumagwa R, Nonga HE, Mdegela RH, Skjerve E. Anthrax outbreaks in the humans - livestock and wildlife interface areas of Northern Tanzania: a retrospective record review 2006-2016. BMC Public Health. 2018;18:106.

25. Lehman MW, Craig AS, Malama C, Kapina-Kany'anga M, Malenga P, Munsaka F, et al. Role of Food Insecurity in Outbreak of Anthrax Infections among Humans and Hippopotamuses Living in a Game Reserve Area, Rural Zambia. Emerg Infect Dis. 2017;23:1471-7.

26. Dixon TC, Meselson M, Guillemin J, Hanna PC. Anthrax. N Engl J Med. 1999;341:815-26.

27. Department of Livestock and Veterinary Services. Zimbabwe Anthrax Control Guidelines in Humans and Animals. 2012. http://apps.who.int/medicinedocs/documents/s20996en/s20996en.pdf. Accessed 15 Feb 2019.

\section{Tables}


Table 1: Attack rates by age and sex during a cutaneous anthrax outbreak: Arua District, Uganda, January 2015 to August $2017(\mathrm{~N}=68)$

\begin{tabular}{llll}
\hline Sex & Frequency & $\begin{array}{l}\text { Total Population } \\
\text { (For the sub-counties) }\end{array}$ & Attack Rate/10,000 \\
\hline Male & 66 & 25666 & 25.71 \\
Female & 2 & 26566 & 0.75 \\
\hline Age group (years) & \multicolumn{3}{c}{ (For the district) } \\
\hline$<10$ & 5 & 270,270 & 1.9 \\
$10-19$ & 7 & 219,380 & 3.2 \\
$20-29$ & 12 & 136,860 & 8.8 \\
$30-39$ & 22 & 85,250 & 26 \\
$40-49$ & 13 & 56,470 & 23 \\
$50+$ & 9 & 62,700 & 14 \\
\hline
\end{tabular}

Table 2

Distribution of exposure status among cases and controls during a cutaneous anthrax outbreak: Arua District, January 2015 to August 2017

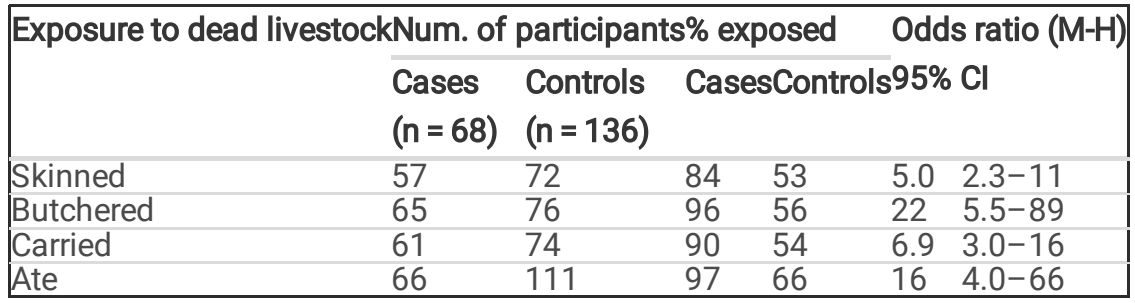

\section{Figures}




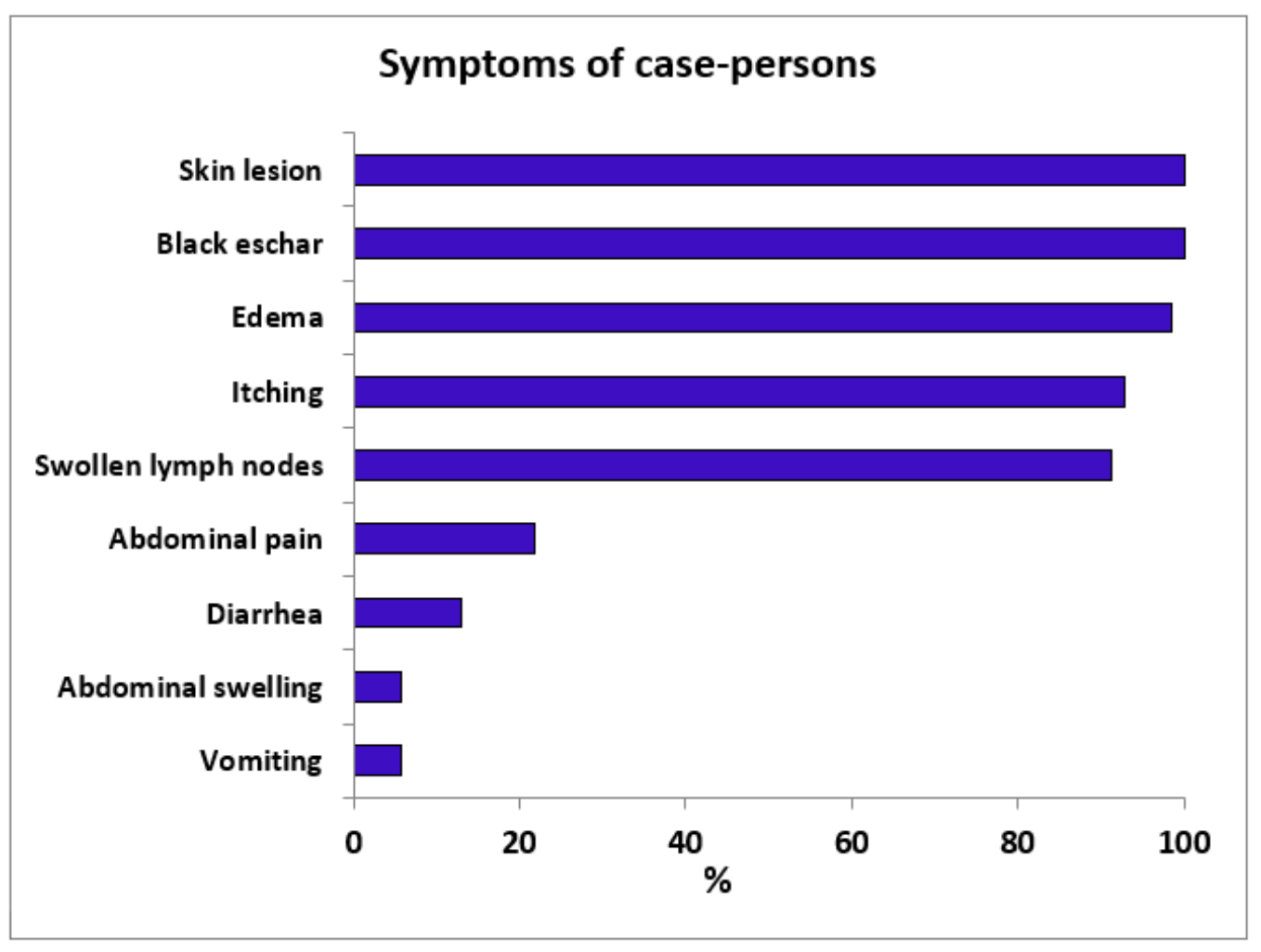

Figure 1

Distribution of symptoms among 68 persons with probable and confirmed cutaneous anthrax: Arua District, Uganda, January 2015 to August 2017

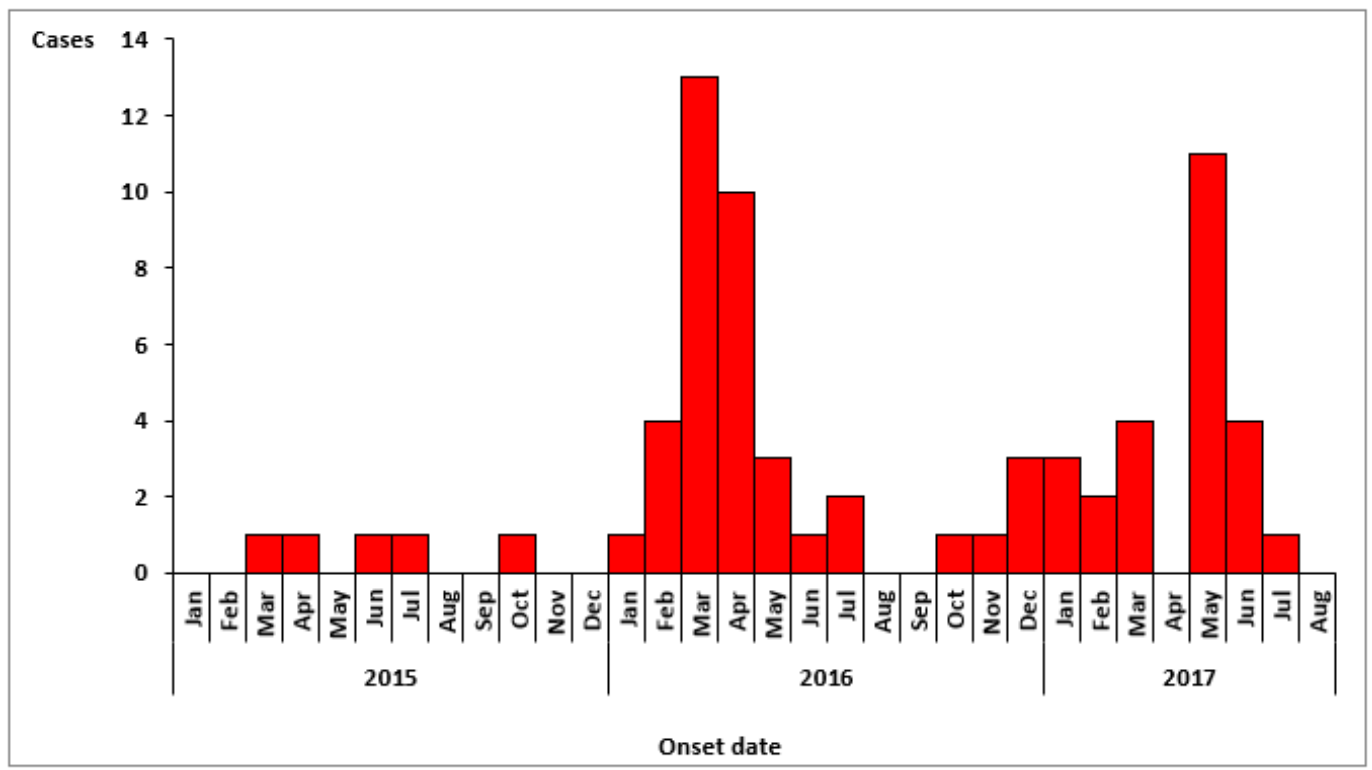

Figure 2

Epidemic curve showing symptom onset dates of persons with probable and confirmed cutaneous anthrax: Arua District, Uganda, January 2015 to August 2017 


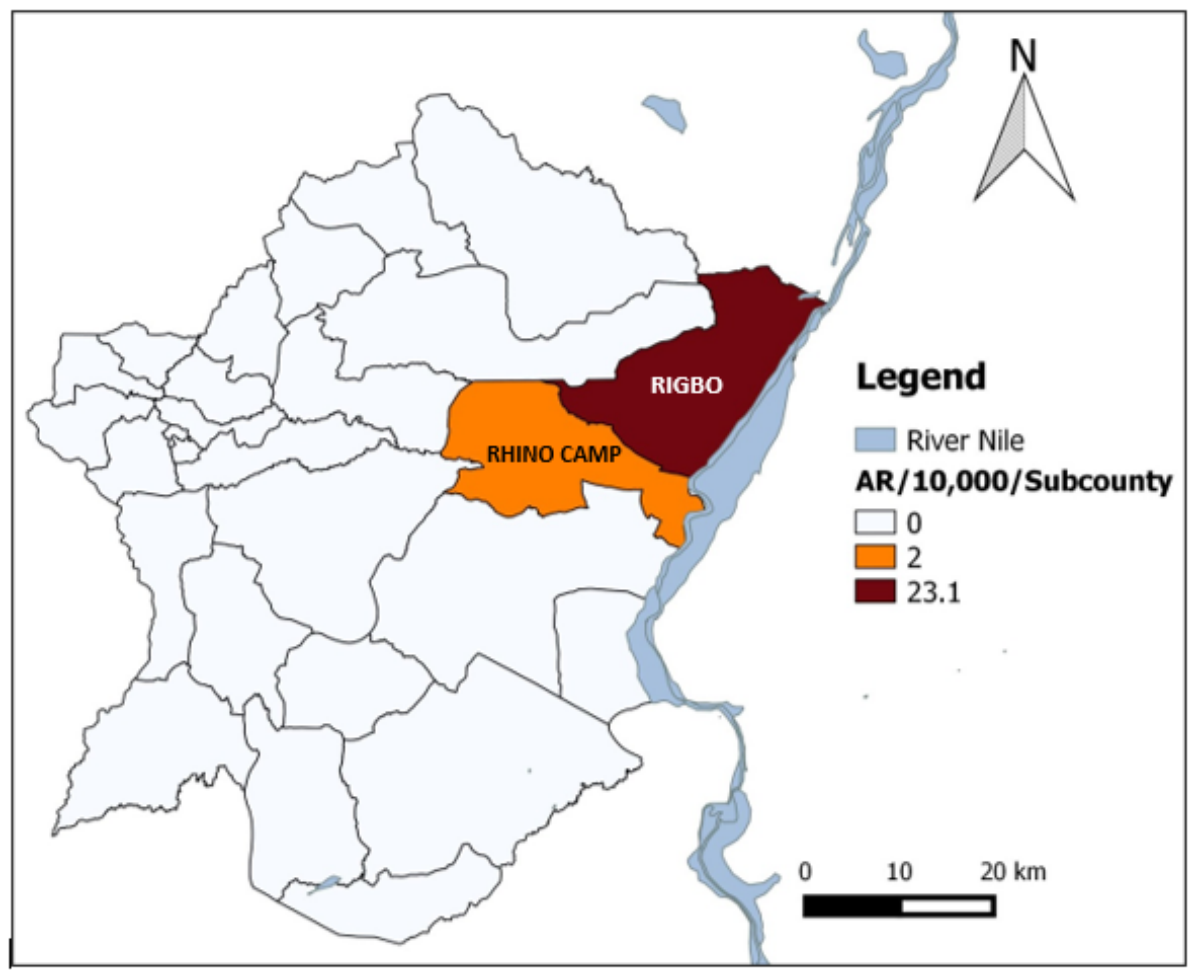

\section{Figure 3}

Map showing the attack rate/10,000 population for the affected sub-counties during a cutaneous anthrax outbreak: Arua District, January 2015 to August 2017, N=68

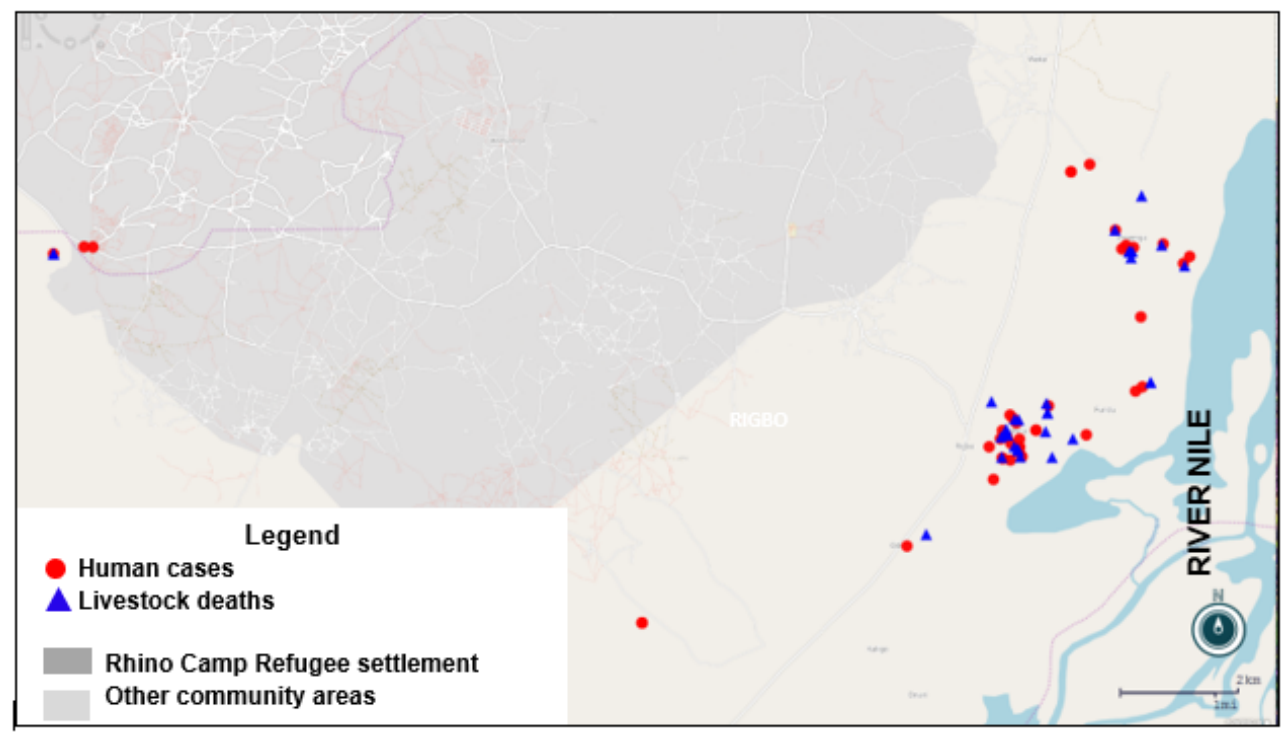

Figure 4

Map showing the locations of livestock deaths and human cases of probable and confirmed anthrax: Arua District, Uganda, January 2015 to August 2017. 